\title{
ANALISIS PENAMBAHAN TRANSFORMATOR SISIPAN UNTUK MENGATASI OVERLOAD PADATRANSFORMATOR DB0244 DI PENYULANG SEBELANGA
}

\author{
Kadek Wahyudi Widiatmika ${ }^{1}$, I Wayan Arta Wijaya ${ }^{2}$, I Nyoman Setiawan ${ }^{3}$ \\ Jurusan Teknik Elektro, Fakultas Teknik Universitas Udayana \\ Email: wahyudiwidiatmika11@gmail.com ${ }^{\underline{1}}$, artawijaya@unud.ad.id ${ }^{2}$, setiawan@unud.ac.id $^{\underline{3}}$
}

\begin{abstract}
Abstrak
Penyulang Sebelanga berada di wilayah PT.PLN (Persero) Area Bali Selatan yang disuplai oleh Gardu Induk Pemecutan Kelod dengan kapasitas penyulang sebesar 280 A. Penyulang Sebelanga mensuplai tranformator DB0244 yang terbebani sebesar 103,4 \% dengan kapasitas 250 kVA. Standarisasi pembebanan untuk sebuah transformator adalah sebesar $80 \%$ dari kapasitas transformator. Solusi untuk mengatasi permasalahan ini adalah dengan melakukan pemasangan transformator sisipan yang bertujuan untuk membagi beban dari transformator DB0244. Berdasarkan data PT. PLN (Persero) Area Bali Selatan tahun 2017 peningkatan penggunanan energi listrik di kota Denpasar setiap tahunnya adalah sebesar 8,3\%. Maka dengan menggunakan transformator sisipan yang berkapasitas $250 \mathrm{kVA}$, dimana persentase pembebanan awal sebesar 26,8\% akan dapat melayani peningkatan penggunaan energi listrik selama lima tahun kedepan dengan total persentase pembebanan setelah lima tahun adalah sebesar 68,3\%.
\end{abstract}

Kata Kunci : Penyulang Sebelanga, Overload Transformator Sisipan

\section{PENDAHULUAN}

Penyulang Sebelanga salah satu penyulang yang disuplai gardu induk Padangsambian. Penyulang ini melayani pendistribusian tenaga listrik di wilayah Sebelanga, Jabapura, dan Umadui. Penyulang Sebelanga memiliki 30 transformator distribusi, dengan kapasitas 100kVA, 160kVA, 250kVA dan 400kVA. [1]

Nilai standar untuk pembebananan transformator adalah 80\%.[2] Persentase pembebanan transformator distribusi DB0244 sebesar 104,3\%.[1] Dengan demikian transformator DB0244 dapat dikatakan mengalami overload.

Berdasarkan permasalahan tersebut maka dalam penelitian ini akan dibahas tentang penambahan dan penempatan transformator distribusi pada Penyulang Sebelanga.

\section{KAJIAN PUSTAKA}

\subsection{Tinjauan Mutakhir}

Penelitian yang dilakukan oleh I Made Aditya Nugraha (2010) yang berjudul
"Analisis Penempatan dan Pemilihan Kapasitas Transformator Distribusi Secara Optimal Pada Penyulang Perumnas". Hasil akhir dari penelitian ini adalah pada transformator DB 257 dilakukan perelokasian dari 250 kVA menjadi 400 kVA. pemerataan beban pada transformator DB 623 sebesar 79 kVA dan penambahan transformator baru yang masing - masing berkapasitas 315 kVA pada transformator distribusi sisipan 1 dan 400 kVA pada transformator distribusi sisipan 2 dan 3. Sedangkan pada transformator distribusi DB 645 dilakukan perelokasian kapasitas transformator distribusi dari 250 kVA menjadi 160 kVA

\subsection{Pembebanan Transformator}

Pemilihan kapasitas transformator distribusi yang sesuai dengan beban konsumen akan menyebabkan efisiensi yang baik. Persentase pembebanan transformator distribusi dapat dicari dengan perbandingan antara daya terpasang dengan kapasitas transformator distribusi, yang dapat 
dinyatakan dalam persen (\%) atau dengan persamaan sebagai berikut.[3]

$$
\text { \%Pembebanan }=\frac{\mathrm{LT}}{\mathrm{P} \mathrm{T}} \times 100 \%
$$

Keterangan:

\%Pembebanan $=$ Persentase pembebanan transformator distribusi (\%)

$\mathrm{LT}=$ Load transformator (VA)

PT = Kapasitas transformatordistribusi (VA)

Untuk menentuan kapasitas transformator yang akan digunakan dapat dirumuskan sebagai berikut: [4]

Keterangan:

$$
\mathrm{P} \mathrm{T}=\frac{\mathrm{L} \mathrm{T}}{0.8}
$$

P T = Kapasitas transformator distribusi (VA)

$\mathrm{L} T=$ Load transformator (VA)

$0,8=$ Batas pembebanan transformator

Kontruksi pemasangan transformator menggunakan kontruksi gardu portal

\subsection{Gardu Portal}

Gardu Portal adalah gardu listrik tipe terbuka (out-door) dengan memakai konstruksi dua tiang atau lebih. Umumnya konfigurasi gardu tiang yang dicatu dari SUTM adalah $T$ section dengan peralatan pengaman Fuse Cut Out (FCO) sebagai pengaman hubungan singkat transformator dan Lightning Arrester (LA) sebagai sarana pencegahan naiknya tegangan pada transformator akibat surja petir.[5]

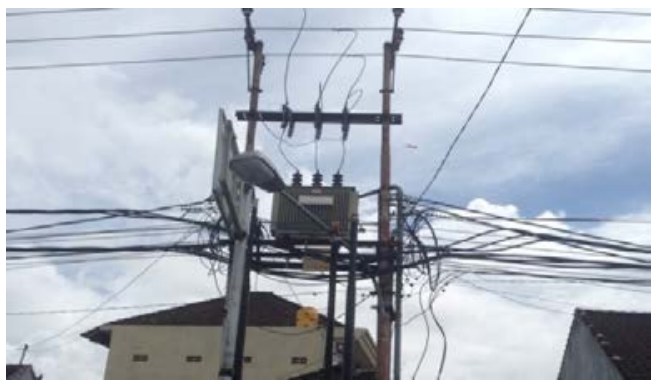

Gambar 1 Gardu Portal

Tiang yang dipergunakan untuk Gardu Distribusi jenis ini dapat berupa tiang besi ataupun tiang beton berkekuatan beban kerja sekurang-kurangnya 500 daN, dengan panjang 11 atau 12 meter.[5]

\section{METODELOGI PENELITIAN}

\subsection{Analisis Data}

Analisis dalam penelitian ini dilakukan dalam beberapa tahapan sebagai berikut:

1. Menghitung pembebanan transformator DB0244.

2. Menghitung kapasitas transformator sisipan.

3. Menghitung pembagian beban jurusan.

4. Menghitung pembebanan selama lima tahun terakhir.

5. Menentukan transformator sisipan berdasarkan konsumsi energi listrik selama lima tahun terakhir.

6. Menentukan lokasi pemasangan transformator sisipan dan kontruksi gardu yang digunakan .

\subsection{Langkah Penelitian}

Langkah penelitian pada penelitian ini adalah sebagai berikut:

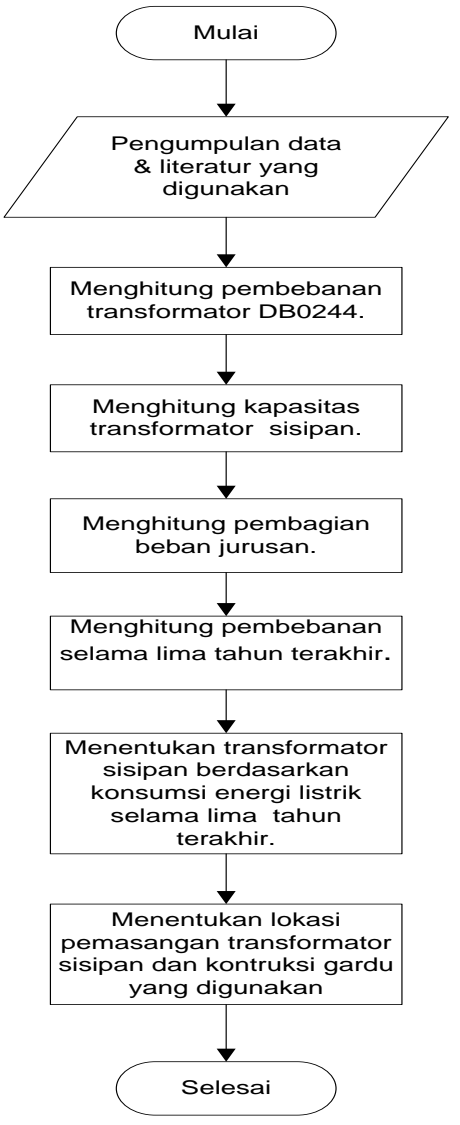

Gambar 2 Diagram Alir Penelitian

\section{HASIL DAN PEMBAHASAN}




\subsection{Gambaran Umum Penyulang Sebelanga}

Penyulang Sebelanga merupakan Penyulang yang terdapat di wilayah PT. PLN (Persero) Area Bali Selatan. Penyulang ini disuplai oleh Gardu Induk Pemecutan Kelod dengan Kapasitas penyulang sebesar $280 \mathrm{~A}$, menggunakan tiga buah sistem penyaluran tenaga listrik yaitu Saluran Kabel Tegangan Menengah (SKTM) dengan jenis penghantar NA2XSEBY 3 x $240 \mathrm{~mm}$ dengan, Saluran Kabel Udara Tegangan Menengah (SKUTM) dengan jenis penghantar MVTIC $3 \times 150+1$ x $50 \mathrm{~mm}$, dan Saluran Udara Tegangan Menengah (SUTM) dengan jenis penghantar AAACS 3 × $150 \mathrm{~mm}$. Terdapat 30 buah transformator yang disuplai Penyulang Sebelanga dengan kapasitas mulai dari 100 kVA, 160 kVA, 250 kVA dan 400 kVA dengan jumlah total sebesar 6170 kVA.[1]

\subsubsection{Kapasitas Penghantar Penyulang Sebelanga}

Spesifikasi pengahantar pada penyulang sebelanga:

Tabel 1 Spesifikasi Pengahantar

\begin{tabular}{|c|c|c|c|}
\hline No & $\begin{array}{c}\text { Jenis } \\
\text { Penghantar }\end{array}$ & $\begin{array}{c}\text { Diameter } \\
\text { Pengahantar }\end{array}$ & $\begin{array}{c}\text { Kapasitas } \\
\text { Hantar } \\
\text { Arus }\end{array}$ \\
\hline 1 & $\begin{array}{c}\text { MVTIC } \\
\text { (NFA2XSY) }\end{array}$ & $\begin{array}{c}3 \times 150 \mathrm{~mm} \\
+50 \mathrm{~mm} \\
\end{array}$ & $326 \mathrm{~A}$ \\
\hline 2 & AAACS & $3 \times 150 \mathrm{~mm}$ & $423 \mathrm{~A}$ \\
\hline 3 & NA2XSEBY & $3 \times 240 \mathrm{~mm}$ & $\begin{array}{l}415 \mathrm{~A} \\
\text { open air, } \\
338 \mathrm{~A} \\
\text { ground }\end{array}$ \\
\hline
\end{tabular}

Sumber : Sutrado Kabel

\subsubsection{Transformator DB024}

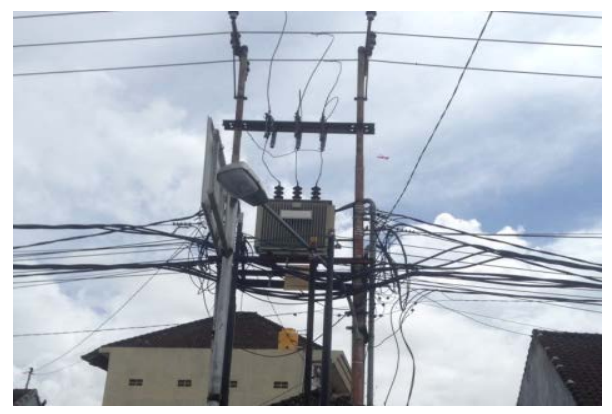

Gambar 3 Transformator DB0244
Berdasarkan data yang diperoleh, transformator distribusi DB 0244 terbagi atas 4 jurusan yaitu jurusan A dengan kawasan Jalan Gunung Soputan sampai Pasar Tunjung, jurusan B dengan kawasan yaitu Perumahan Pondok Galeria, jurusan C dengan kawasan yaitu Perumahan Taman Umadui blok $A$ dan blok $B$ dan yang terakhir jurusan D yaitu dengan kawasan yaitu Perumahan Taman Umadui blok C, blok D dan blok E.[1]

Data hasil pengukuran transformator DB0244 pada tahun 2017 yang dilakukan oleh PT. PLN (Persero) Area Bali Selatan :

1. Tanggal Pengukuran : 12/6/2017

2. Jam Pengukuran : $19: 52$ Wita

3. IR , IS , IT ,IN: 526A , 326A , 312A , 172A

4. Jurusan $A$ IR , IS , IT , IN : 286A , 136A, 175A , 91A

5. Jurusan $B$ IR , IS , IT , IN : 97A , 99A , 76 , 36A

6. Jurusan $\mathrm{C}$ IR , IS , IT , IN : 31A , 55A , 27A , 38A

7. Jurusan D IR , IS , IT , IN : 123A , 31A , 31A , 73A

8. Kapasitas Transformator : 250 kVA

9. Pembebanan Transformator : 261 kVA

10. Tegangan Induk Fasa

RS ,RT,ST : 387 V, 399 V,386 V

\subsubsection{Persentase pembebanan Transformator DB0244}

Data pembebanan transformator DB0244 dari tahun 2010 sampai tahun 2015.

Tabel 2 Persentase Pembebanan Transformator DB0244 Tahun 2010 -2015

\begin{tabular}{|c|c|c|}
\hline No & Waktu Pengukuran & $\begin{array}{c}\text { Dibebani } \\
(\%)\end{array}$ \\
\hline 1 & 9 Maret 2010 Pukul 19:57:40 Wita & 106.11 \\
\hline 2 & 24 Juni 2011 Pukul 18:47:16 Wita & 99.04 \\
\hline 3 & 6 Juni 2012 Pukul 18:47:19 Wita & 99.04 \\
\hline 4 & 18 Juni 2013 Pukul 20:24:11 Wita & 105.95 \\
\hline 5 & 06 Juli 2014 Pukul 20:20:00 Wita & 113.24 \\
\hline 6 & 7April 2015 Pukul 20:02:00 Wita & 107.84 \\
\hline
\end{tabular}

Sumber : PT. PLN (Persero) Rayon Denpasar, 2017

\subsection{Perhitungan Transformator Sisipan}




\subsubsection{Perhitungan Pembebanan Transformator DB0244}

Nilai pembebanan transformator dapat dihitung dengan menggunakan rumus :

$\%$ Pembebanan $=\frac{\mathrm{L} \mathrm{T}}{\mathrm{P} \mathrm{T}} \times 100 \%$

\%Pembebanan $=\frac{\mathrm{I}_{\mathrm{AV}} \times \mathrm{V}_{\mathrm{AV}} \times \sqrt{3}}{\mathrm{P} \mathrm{T}} \times 100 \%$

$\%$ Pembebanan $=\frac{388 \times 391 \times \sqrt{3}}{250.000} \times 100 \%$

\%Pembebanan $=104.9 \%$

Keterangan:

\%Pembebanan $=$ Persentase pembebanan transformator distribusi (\%)

$\mathrm{LT}=$ Load transformator (VA)

PT = Kapasitas transformatordistribusi (VA)

$\mathrm{I}_{\mathrm{AV}}=$ Arus rata-rata $(\mathrm{A})$

$\mathrm{V}_{\mathrm{AV}}=$ Tegangan rata-rata $(\mathrm{V})$

\subsubsection{Perhitungan Kapasitas}

Transformator Sisipan

Nilai persentase pembebanan setelah dilakukan pemasangan transformator sisipan 100 kVA dirumuskan dengan :

$\%$ Pembebanan $=\frac{\mathrm{LT}}{\mathrm{P} \mathrm{T}} \times 100 \%$

$\%$ Pembebanan $=\frac{\mathrm{I}_{\mathrm{AV}} \times \mathrm{V}_{\mathrm{AV}} \times \sqrt{3}}{\mathrm{P} \mathrm{T}} \times 100 \%$

$\%$ Pembebanan $=\frac{388 \times 391 \times \sqrt{3}}{250.000+100.000} \times 100 \%$

\%Pembebanan $=74.9 \%$

Keterangan:

\%Pembebanan $=$ Persentase pembebanan transformator distribusi (\%)

$\mathrm{LT}=$ Load transformator (VA)

PT = Kapasitas transformatordistribusi (VA)

$\mathrm{I}_{\mathrm{AV}}=$ Arus rata-rata $(\mathrm{A})$

$\mathrm{V}_{\mathrm{AV}}=$ Tegangan rata-rata $(\mathrm{V})$

Dengan menggunakan rumus yang sama, maka persentase pembebanan setelah dilakukan pemasangan transformator sisipan dengan kapasitas 100 kVA, 160 kVA, 250 kVA, 400 kVA dapat dilihat pada tabel 3.

Tabel 3 Persentase Pembebanan Transforator Berdasarkan Kapasitas Transformator Siaipan

\begin{tabular}{|c|c|c|c|c|}
\hline No & $\begin{array}{c}\text { Kapasitas } \\
\text { Transformator } \\
\text { DB0244 } \\
\text { (kVA) }\end{array}$ & $\begin{array}{c}\text { Pembebanan } \\
\mathbf{( \% )}\end{array}$ & $\begin{array}{c}\text { Kapasitas } \\
\text { Transformator } \\
\text { Sisipan } \\
\text { (kVA) }\end{array}$ & $\begin{array}{c}\text { Pembebanan } \\
\mathbf{( \% )}\end{array}$ \\
\hline 1 & 250 & 104.9 & 100 & 74.9 \\
\hline 2 & 250 & 104.9 & 160 & 64.0 \\
\hline 3 & 250 & 104.9 & 250 & 52.4 \\
\hline 4 & 250 & 104.9 & 400 & 40.3 \\
\hline
\end{tabular}

\subsection{Pembagian Beban jurusan}

Perhitungan persentase pembebanan setelah dilakukan pembagian beban jurusan untuk beban jurusan A dan B dirumuskan dengan:

$$
\begin{aligned}
& \text { \%Pembebanan }=\frac{\mathrm{I}_{\mathrm{AV}} \times \mathrm{V}_{\mathrm{AV}} \times \sqrt{3}}{\mathrm{P} \mathrm{T}} \times 100 \% \\
& \% \text { Pembebanan }=\frac{289.6 \times 391 \times \sqrt{3}}{250.000} \times 100 \% \\
& \text { \%Pembebanan }=78.3 \%
\end{aligned}
$$

Keterangan:

PT = Kapasitas transformatordistribusi (VA)

$\mathrm{I}_{\mathrm{AV}}=$ Arus rata-rata $(\mathrm{A})$

$\mathrm{V}_{\mathrm{AV}}=$ Tegangan rata-rata $(\mathrm{V})$

Nilai persentase beban jurusan $C$ dan $D$ dengan transformator sisipan 100 kVA dirumuskan dengan:

$\%$ Pembebanan $=\frac{\mathrm{I}_{\mathrm{AV}} \times \mathrm{V}_{\mathrm{AV}} \times \sqrt{3}}{\mathrm{P} \mathrm{T}} \times 100 \%$

$\%$ Pembebanan $=\frac{99.3 \times 391 \times 1.73}{100.000} \times 100 \%$

$\%$ Pembebanan $=67.1 \%$

Dengan menggunakan rumus yang sama, maka persentase pembebanan transformator berdasarkan beban jurusan dengan kapasitas 160 kVA, 250 kVA, 400 kVA dapat dilihat pada tabel 4.

Tabel 4 Persentase Pembebanan Transformator Berdasarkan Pembagian Jurusan

\begin{tabular}{|c|c|c|c|}
\hline No & $\begin{array}{c}\text { Kapasitas } \\
(\mathbf{k V A})\end{array}$ & Jurusan & $\begin{array}{c}\text { Pembebanan } \\
(\%)\end{array}$ \\
\hline 1 & 250 & A + B & 78.3 \\
\hline 2 & 100 & C + D & 67.1 \\
\hline 3 & 160 & C + D & 41.9 \\
\hline 4 & 250 & C + D & 26.8 \\
\hline 5 & 400 & C + D & 16.7 \\
\hline
\end{tabular}




\subsection{Penentuan Transformator Sisispan Berdasarkan Konsumsi Energi Listrik}

Data penjualan energi listrik di wilayah denpasar dalam kurun waktu lima tahun terakhir dapat dilihat pada tabel 5.

Tabel 5 Konsumsi Energi Listrik di Denpasar

\begin{tabular}{|c|c|c|}
\hline No & Tahun & $\begin{array}{c}\text { kWH Jual } \\
\text { (kWH) }\end{array}$ \\
\hline 1 & 2012 & 1.914 .581 .169 \\
\hline 2 & 2013 & 2.069 .912 .879 \\
\hline 3 & 2014 & 2.274 .858 .569 \\
\hline 4 & 2015 & 2.364 .973 .992 \\
\hline 5 & 2016 & 2.629 .710 .762 \\
\hline
\end{tabular}

Sumber : PT. PLN (Persero) Rayon Denpasar, 2017

Untuk menentukan persentase peningkatan penggunaan energi listrik dapat dirumuskan dengan :

$$
\% \mathrm{KEL}=\frac{\mathrm{KE} \mathrm{L_{N } - K E L _ { \mathrm { P } }}}{\mathrm{KE} \mathrm{L} \mathrm{L}_{\mathrm{P}}} \times 100 \%
$$

Keterangan:

$\% \mathrm{KEL}=$ Persentase Konsumsi Energi Listrik (\%)

$\mathrm{KEL}_{\mathrm{N}}=$ Konsumsi Energi Listrik Akhir

$\mathrm{KEL}_{\mathrm{P}}=$ Konsumsi Energi Listrik Awal

Persentase konsumsi energi listrik di Denpasar tahun 2012-2013

$$
\begin{aligned}
\% \mathrm{~K} E \mathrm{~L}=\frac{2.069 .912 .879-1.914 .581 .169}{} \\
\begin{array}{c}
1.914 .581 .169 \\
\times 100 \%
\end{array}
\end{aligned}
$$

$\% \mathrm{~K} \mathrm{E} \mathrm{L}=8.1 \%$

Dengan menggunakan rumus yang sama, maka hasil perhitungan konsumsi energi listrikdi Denpasar tahun 2013-2014, 2014-2015 dan 2015-2016 dapat dilihat pada tabel 6

Tabel 6 Persentase Konsumsi Energi Listrik di Denpasar

\begin{tabular}{|c|c|c|}
\hline No & Tahun & $\begin{array}{c}\text { Konsumsi Energi } \\
\text { Listrik }\end{array}$ \\
\hline 1 & $2012-2013$ & $8,1 \%$ \\
\hline 2 & $2013-2014$ & $9,9 \%$ \\
\hline 3 & $2014-2015$ & $3,9 \%$ \\
\hline 4 & $2015-2016$ & $11,1 \%$ \\
\hline
\end{tabular}

Jadi berdasarkan tabel diatas, maka dengan menggunakan transformator sisipan yang berkapasitas sebesar 250 kVA dengan persentase pembebanan awal sebesar $26,8 \%$ akan dapat melayani peningkatan penggunaan energi listrik selama lima tahun kedepan dengan total pembebanan setelah lima tahun adalah sebesar $68,3 \%$.

\subsection{Penempatan Transformator \\ Sisipan}

Berdasarkan perancangan dan konstruksi, transformator sisipan akan menggunakan perancangan gardu portal yaitu menggunakan konstruksi dua buah tiang beton dengan tinggi 13 meter dan beban kerja 350 daN per tiang. Untuk penempatan kubikel menggunakan jenis RMU/Modular dalam lemari panel (metal clad). Kapasitas transformator yang digunakan adalah sebesar 250 kVA yang akan dibagi menjadi dua jurusan. Berdasarkan standar aturan PLN, pemasangan Gardu Distribusi jenis tiang besi maupun tiang beton harus memiliki beban kerja minimal yaitu 500 daN, dengan panjang 11 atau 12 meter.[4] 


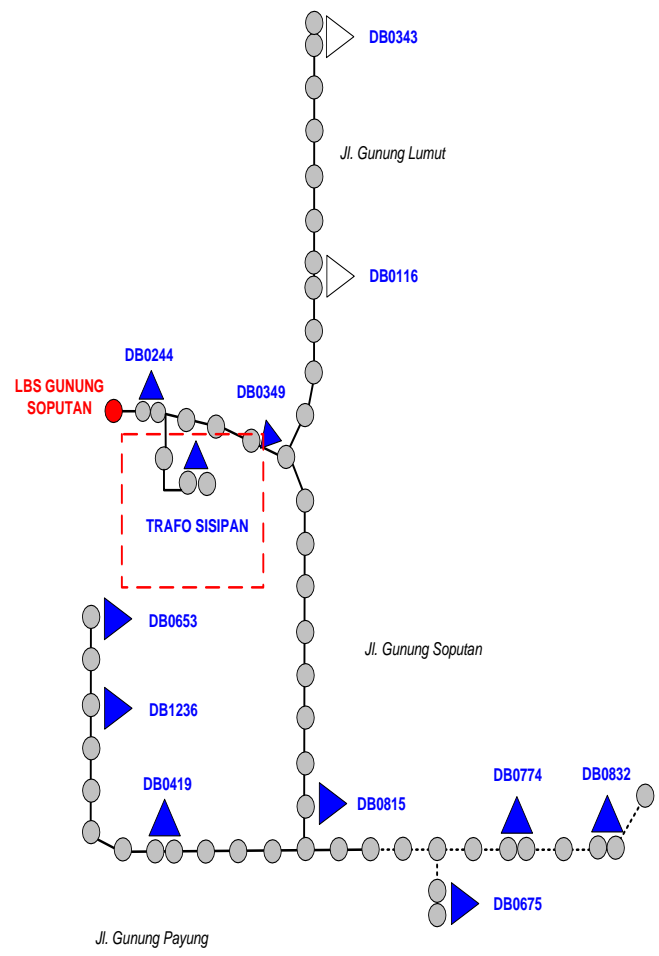

Gambar 4 Lokasi Penempatan Transformator Sisipan Lokasi untuk menempatkan transformator sisipan terletak di Perumahan Taman Umadui Blok A, dengan jarak kurang lebih seratus meter dari transformator DB0244. Sehingga dengan menempatkan transformator sisipan di Perumahan Taman Umadui Blok A, maka tidak perlu dilakukan pemindahan jalur jurusan karena jurusan $\mathrm{C}$ dan $D$ adalah jurusan yang menyuplai energi listrik ke Perumahan Taman Umadui.

\section{SIMPULAN}

Simpulan yang dapat diambil berdasarkan hasil pengujian dan pembahasan yang telah dilakukan adalah sebagai berikut:

1. Dengan menggunakan transformator sisipan 250 kVA, persentase pembebanan awal sebesar $26,8 \%$ atau $68,3 \%$.selama lima tahun kedepan

2. Transformator sisipan menggunakan perancangan gardu portal konstruksi dua buah tiang beton dengan tinggi 13 meter dan beban kerja 350 daN per tiang. Lokasi untuk menempatkan transformator sisipan terletak di Perumahan Taman Umadui Blok A, dengan jarak kurang lebih seratus meter dari transformator DB0244.

\section{DAFTAR PUSTAKA}

[1] PT.PLN (Persero) Area Bali Selatan. Data Pengukuran Transformator Penyulang Sebelanga.2017

[2] Aditya, N. Analisis Penempatan dan Pemilihan Kapasitas Transformator Distribusi Secara Optimal Pada Penyulang Perumnas. Bali: Universitas Udayana: 2010.

[3] Berahim, H. Pengantar Teknik Tenaga Listrik Teori Ringkas dan Penyelesaian Soal. Yogyakarta: Andi Offset. 1996.8-11

[4] Warman. Pemilihandan Peningkatan Penggunaan I Pemakaian Serta Manajement Trafo Distribusi. Sumatera Utara : Universitas Sumatra Utara: 2004.

[5] Anonim. Buku 4 Standar Konstruksi Gardu Distribusi dan Gardu Hubung 
Tenaga Listrik. Jakarta Selatan: PT

PLN (PERSERO). 2010:21-25

[6] PT. PLN (Persero) Rayon Denpasar. Data Konsumsi Energi Listrik Tahun 2012 - 2016.

[7] PT.PLN (Persero) Area Bali Selatan. Data pembebanan transformator DB0244. 2017 